\title{
Hydrologic Restoration in the Urban Environment Using Green Roofs
}

\author{
Anna Palla *, Ilaria Gnecco and Luca G. Lanza \\ Department of Civil, Environmental and Architectural Engineering, University of Genova, \\ Via Montallegro 1, 16145 Genoa, Italy; E-Mails: ilaria.gnecco@unige.it (I.L.); \\ luca.lanza@unige.it (L.G.L.) \\ * Author to whom correspondence should be addressed; E-Mail: anna.palla@unige.it; \\ Tel.: +39-010-353-2301; Fax: +39-010-353-2481.
}

Received: 18 January 2010; in revised form: 3 March 2010 / Accepted: 30 March 2010 / Published: 9 April 2010

\begin{abstract}
Loss of natural soil and vegetation within the urban environment can significantly affect the hydrologic cycle by increasing storm water runoff rates and volumes. In order to mitigate these modifications in urban areas engineered systems are developed, such as green roofs, to mimic and replace functions (evapo-transpiration, infiltration, percolation) which have been altered due to the impact of human development. Green roofs, also known as vegetated roof covers, eco-roofs or nature roofs, are composite complex layered structures with specific environmental benefits. They are increasingly being used as a source control measure for urban storm water management. Indeed, they are able to re-establish the natural water cycle processes and to operate hydrologic control over storm water runoff with a derived peak flow attenuation, runoff volume reduction and increase of the time of concentration. Furthermore green roofs exhibit the capacity to reduce storm water pollution; they generally act as a storage device, consequently pollutants are accumulated in the substrate layer and released when intensive rainwater washes them out. In order to investigate the hydrologic response of a green roof, the University of Genova recently developed a joint laboratory and full-scale monitoring programme by installing a "controlled" laboratory test-bed with known rainfall input and a companion green roof experimental site $(40 \mathrm{~cm}$ depth) in the town of Genoa. In the paper, data collected during the monitoring programme are presented and compared with literature data.
\end{abstract}


Keywords: green roofs; hydrologic restoration; storm water; pollution; urban hydrology

\section{Introduction}

As development progresses in a urban environment the impervious areas increase with the direct consequence of higher runoff rates and volumes and shorter times of concentration. Indeed, the impervious surfaces rapidly contribute runoff to the receiving water bodies while the pervious areas store and deliver subsurface flow over periods of hours, days or weeks. The construction of impervious surfaces modifies the surrounding soils through engineered compaction and eliminates superficial soil and its role as a significant pervious storage interface between the subsurface and the atmosphere.

Traditional storm water management in urban areas aims at removing runoff as quickly as possible, eventually gathering excess runoff in detention basins for peak reduction. The conventional approach to storm water management involves the efficient capture, conveyance and sometimes treatment of runoff generated from the impervious surfaces. Sustainable Urban Drainage Systems (SUDS), Low Impact Development (LID) or Water Sensitive Urban Design (WSUD) principles and applications are a relatively new approach to storm water management that represent a conceptual improvement from the conventional sewer system design methodology [1]. LIDs (SUDS or WSUDs) are basically a source reduction approach. These sustainable strategies focus on evaporating, transpiring and infiltrating storm water on-site through natural and/or engineered soil, vegetation and bioengineering applications to reduce and treat the overland flow that is limited for most rainfall events in a natural environment.

LIDs are a way of managing storm water and planning the land development, at the parcel and catchment scale, that emphasize conservation and use of on-site natural features integrated with engineered source controls to more closely mimic the pre-development hydrologic functions. LID solutions include storm water infiltration systems, rain gardens, storm water wetlands, green roofs, etc. to be properly distributed throughout the urban area. The positive aspects of these alternative approaches are that, in addition to reducing surface runoff, it may also be possible to increase recharge of local ground water resources and streams, reduce stream erosion, favor the development of biodiversity and improve stream water quality.

Site planning and storm water management have to be integrated at the initial design phases of a urban project to maintain a more hydrologically functional landscape. Hydrology and natural site features that influence water movement have to guide the layout of roads, structures and infrastructures. Natural soil and vegetation protections, that are strategically distributed throughout the landscape to slow, store and infiltrate storm water flows, are designed into the new projects as amenities, as well as hydrologic controls.

Several studies have been conducted to analyze the effectiveness of various LID (or SUDS or WSUD) practices based on hydrologic and pollutant removal capabilities. Bioretention areas, grass swales, permeable pavements and green roofs are the most common practices investigated in the literature. These techniques are able to reduce the amount of Effective Impervious Area (EIA) in a watershed. EIA is the impervious area directly connected to the storm drainage system and contributes 
to increased watershed volumes and runoff rates. There are documented case studies that conclusively link urbanization and increased watershed imperviousness to hydrologic impacts on streams.

Kleidorfer et al. [2] analyzed e.g. the impact of urbanization, expressed by the increase of impervious area, in conjunction with possible global warming scenarios on urban hydrology and in particular on the efficiency of a combined sewer system. It is shown that a $20 \%$ increase of a climate change factor expressed in terms of rain intensity distribution has the same effect, on average, as a $40 \%$ increase of the impervious area. Such an increase of rainfall intensities could be compensated, on average, by infiltration measures which lead to a 30\% reduction of the impervious area. They concluded that the impact of increased urbanization is sometimes significantly higher than the one expected from global warming.

LID could become a viable approach to reduce Combined Sewer Overflows (CSO), however LID has not been widely implemented in highly urbanized areas due to a perception that insufficient land is available. LID systems could become most effective when applied on private areas, e.g. green roofs on private rooftops, which occupy a large fraction of the land surface in the urban environment [3].

The goal of the present paper is to account for relevant research on green roof systems as hydrological restoration solutions, and to synthesize the results so that the current status and future research needs can be assessed. In Section 2 the basic green roof technology is recalled and a review of experimental evidences about the related hydrologic performance is presented based on literature results. Section 3 is devoted to the description of a joint laboratory and full-scale monitoring programme undertaken at the University of Genova (Italy) to investigate hydrologic green roof performance in a Mediterranean environment. Finally conclusions are drawn in Section 4.

\section{Hydrologic performance of a green roof}

Green roofs, also known as vegetated roof covers, eco-roofs or living roofs, are a complex layered structure. Typically, above the water-proof membrane and the mechanic protection geotextile, a drainage layer is designed (implemented with either some engineered coarse grained porous media or plastic profiled elements) to carry infiltrated rain water to roof drains, and to store water for the plants in dry periods. Next, a filter fabric is installed to prevent soil from washing away and compromising the drainage layer as water drains from the roof. Finally, the plants and the associated substrate, or growing layer (a blend of mineral material enriched with organic material), complete the green roof system.

The available technical solutions for green roof construction are usually categorized in three classes: intensive, semi-intensive and extensive. The differences are essentially based on the thickness of the stratigraphy, the expected use of the rooftop, and the costs required for maintenance. Intensive green roofs are thick and therefore heavy systems used to obtain a generally practicable rooftop with significant maintenance efforts required. Extensive green roofs are lightweight, thin systems that generally do not require maintenance and can not be walked on for any use. Semi-intensive solutions are middle way systems. 


\subsection{Storm water quantity}

The main performance of green roofs in the quantitative management of storm water is the reduction of the outflow volumes at the annual scale (volume retention), thanks to the losses due to the water requirements of plants and the evapo-transpiration process from vegetation and exposed surfaces.

From the point of view of storm water management, it is of interest to investigate how green-roofs perform seasonally over the long term. Bengtsson [4] used the water balance approach to study the hydrology of a Sedum green roof in Augustenborg, a residential area in Malmö, southern Sweden. It was found that annual outflow can be reduced by up to $64 \%$ due to evapotranspiration. Studies carried out in other countries have demonstrated similar results. Stovin [5] for a small scale instrumented green roof test plot in Sheffield (UK) has shown an average volume retention of 34\% during spring. According to Kohler et al. [6], evaporation from green roofs in Germany (5 and $12 \mathrm{~cm}$ depth) can account for $60-80 \%$ of the annual precipitation.

Based on examples from cities such as Chicago, Philadelphia and Portland, Scholtz-Barth [7] claimed that, on average, $65 \%$ of rainwater was retained by extensive green-roofs in the United States. From a review of the literature, it is clear that volume retention capability on a yearly basis is the most investigated hydrologic performance and the most consistent. It may range from $40 \%$ to $80 \%$ of the total rainfall volume (see Figure 1) with the actual magnitude of retention being a function of the structure of the green roof (the layout of layers and the related depths), the climatic conditions and the amount of precipitation [8-11].

The monitored green roofs involve substrates of different depth, and some researchers have specifically investigated the effects of substrate depth on volume retention [12]. Although increased depths resulted in higher retention, the gain was not large. In general, for the studies examined, increasing the thickness of the substrate did not result in significant gains in volume retention: as an example, Scholtz-Barth [7] observed that for substrate thickness ranging from 2 to $15 \mathrm{~cm}$, the volume retention increases from $58 \%$ to $72 \%$.

However the characteristics of substrates are among the most important factors for volume retention. The effect of vegetation is much-less an effect in aiding water retention when compared with the substrate hydraulic properties [13]. However vegetation plays other important roles providing transpiration cooling shade as well as some mitigation of the urban heat island.

The effect of slope on rainfall retention is unclear. In Germany, Schade [14] and Liesecke [15] found no significant difference in retention amounts across differently sloped roofs. Other studies suggest increasing outflow with increased slope $[12,16]$. The contradicting results may be due to varying rainfall patterns in different environments. The influence of the rooftop slope on retention, as a function of the rainfall intensity, is investigated by Van Woert et al. [12]. As expected, for light rainfall categories, the green roof built on $2 \%$ slope and $4 \mathrm{~cm}$ depth retained a larger amount of water than the one built on $6.5 \%$ slope, but it work differently for the heavy rain intensity.

Volume detention (temporary storage and eventual slow release) determines the attenuation and delay of storm water runoff peaks at the inflow into the drainage network. Peak attenuation is due to the storage capacity of the soil short of the field capacity, to the storage capacity of the drain layer, as well as to the slope of the roof and depends on the shape of the rain hyetograph and the soil moisture 
conditions. The green roof peak outflow rates are reduced to $22-70 \%$ that of a standard roof surface, with greater percent reductions associated with deeper roofs $[17,5]$.

Figure 1. Annual volume retention observed at experimental sites from a literature review.
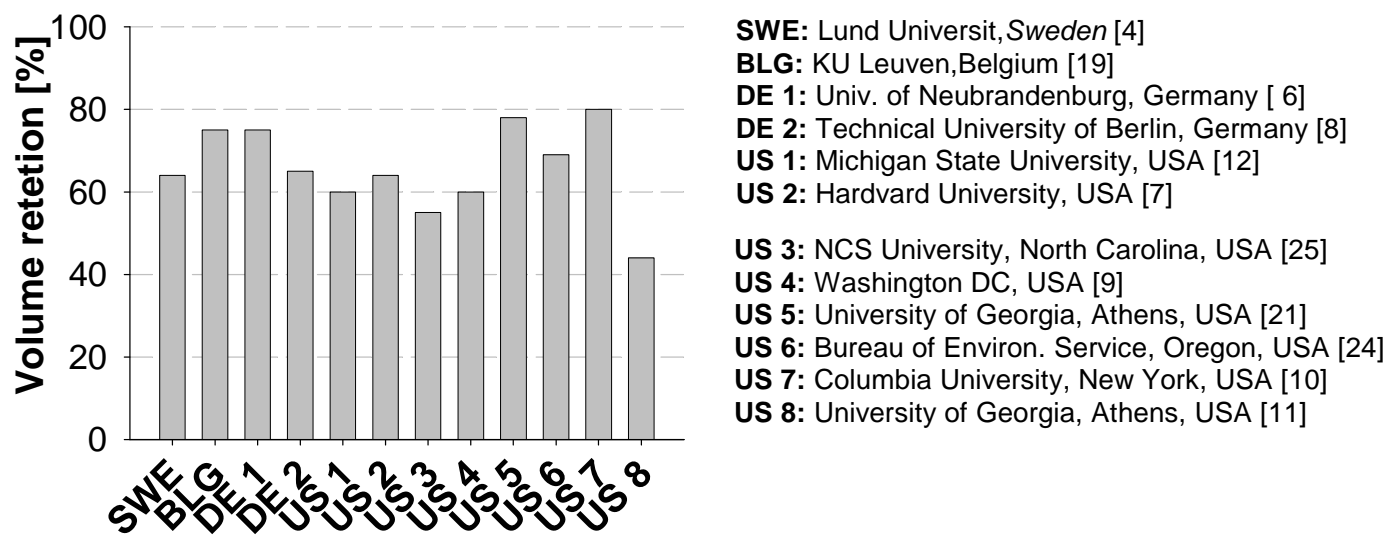

The delay between the time when rainfall starts and runoff begins to flow on the green roof is due to the time needed for the soil to start draining (to reach field capacity). Generally, runoff continues to flow from the green roof for an extended period of time after runoff has stopped flowing from the impervious roof. This delay is because water entering the green roof must filter through the soil, drainage and filter layers before it can outflow from the roof. The green roof delay values are relevant in view of the usual concentration times of urban catchments (see e.g. [18]).

The moisture content of the substrates immediately before a rain event significantly influences water retention and detention. The soil matrix has a specific moisture saturation value and dry soil retains significantly more water than wet soil. For instance, when the soil is near to saturation at the beginning of a rain event, only a small portion of water can be accommodated in void spaces. When the water content is approximately equal to field capacity, however, the green roof is able to detain around $60 \%$ of rain before producing any outflow [18].

As shown by the effect of the volumetric water content on the outflow volumes, if the moisture content immediately before a rain event is equal to residual moisture most of the water will not contribute to the outflow but is retained by the green roof substrates.

Evaluating storm water retention and detention performance of a green roof at the rooftop scale is a valuable first step in determining the feasibility of using green roofs as sustainable storm water management systems. Another important aspect is to investigate how green roofs can be incorporated into a suitable plan for a developed or developing urban catchment. This involves modeling the watershed response to hypothetical roof greening scenarios [19].

Villarreal et al. [20] demonstrated how green roofs can be used to increase storm water storage as part of an inner city urban storm water retrofit project in Sweden. Investigations at a range of spatial scales, from individual rooftop to the entire watershed, can provide comprehensive guidance for effective ways to establish green roofs as a viable LID system. Alfredo et al. [17] conducted laboratory tests on a prototype green roof plot and concluded that, if green roofs were installed on the estimated 6,600 hectares of New York City rooftops potentially eligible for green roof conversion, the volume of 
annual runoff would be reduced by approximately $2 \%$. Carter and Jackson [21] examine the influence of vegetated roofs on storm water runoff volumes at a variety of spatial scales in a highly urbanized watershed in the Piedmont region of Georgia, USA. The additional storage provided by green roofs in this watershed reduces the total peak runoff volumes in the watershed significantly [21].

This decline in peak flow volumes reduces the frequency of the bankfull flow events which may result in changes in bankfull cross-section dimensions originally expanded during urbanization. For future storm sewer retrofitting options, reductions in peak flow volumes from roof greening could provide economic benefits through decreasing the sizing of culverts and pipes designed for large storm events. The volume reduction for flat roofing scenarios will primarily come from the zones of the watershed where impervious areas are most directly connected to the storm sewer system [22]. Reducing the storm water contribution of these impervious surfaces in the watershed is particularly important due to their disproportionate influence on the health of receiving water bodies [23].

\subsection{Storm water quality}

The quality of sub-surface flow water from a green roof (types of contaminants and the related concentration) depends on several factors: the building technique (depth and composition of the soil layer, type of vegetation and drainage layer), the maintenance operations, the land use characteristics of the surrounding environment (residential or industrial areas), the presence of local sources of pollutants and the age of the roof (time elapsed since the installation). Green roofs generally act as a storage device: pollutants are accumulated in the substrate layers and released when intensive rainwater washes them out. Due to evapo-transpiration, some of the constituents dissolved in the soil water precipitate and bind to the soil or to the solid matrix of the drainage layer. Precipitated components can be washed off by rainfall events and transported by the subsurface flow water. Modifications to the physical-chemical parameters, mainly connected to the growing up of vegetation in time and the interaction between the root system, the use of fertilizers, the composition of the soil and the drainage layer can affect the absorption of some metals and organic compounds producing their release [24].

The studies on the quality of the outflow water from a green roof are based on monitoring programmes performed on plots with dimensions in the order of one square meter or on existing green roofs. The release of Total Phosphorus (TP) and Total Nitrogen (TN) need to be carefully considered when installing green roofs. In many cases, the large reduction in storm water volumes will offset a corresponding increase in concentration [25]. The $\mathrm{pH}$ levels from green roofs are consistently slightly basic, with readings ranging from 7.5 to 8.3. Rain samples are slightly acidic, with a pH between 6 and 7. It appears that green roofs have the effect of mitigating mild acid rain [26].

In the first part of its expected lifetime, the green roof operates as a source of nutrients, especially phosphorous, due to the presence of fertilizers in the soil, while it behaves as a sink for metals, with significant reduction with respect to the initial mass at the annual scale [27]. Experimental programmes, conducted on an intensive green roof in Japan and on an extensive green roof in Sweden, show that: both extensive and intensive vegetated roofs are a sink of nitrate nitrogen $\left(\mathrm{NO}_{3}-\mathrm{N}\right)$ and ammonium nitrogen $\left(\mathrm{NH}_{4}-\mathrm{N}\right)$ with similar performance; the intensive vegetated roof is also a sink of Tot-N; while release of phosphorus (most in terms of $\mathrm{PO}_{4}-\mathrm{P}$ ) is observed from both rooftops [28]. 
The green roof has considerable effects - both positive and negative - on the quality of outflow water. This depends on the characteristics of the outflow: the slower the runoff rate, the higher the concentration of total $\mathrm{N}, \mathrm{NH}_{4}-\mathrm{N}$ and organic material $\left(\mathrm{BOD}_{7}\right.$ and $\mathrm{COD}$ ) in the runoff water. Total $\mathrm{P}$ concentration did not vary significantly in relation to water discharge. On the contrary heavy rain washed more phosphates and also nitrates out of the green roof. In snow melting water, the concentration of all components was greater on the green roof due to the accumulation of atmospheric pollutants in snow [29].

It is also clear that the materials used in the substrate layer have an important influence on runoff quality. Alsup et al. [30] characterized the content and exchangeability of metals and micronutrients in several green roof substrates (Arkalyte, Haydite, Lassenite, lava rock, etc.) and investigated whether the presence of vegetation would alter the leaching characteristics of the substrates. The experimental results performed at the Southern Illinois University show that none substrate is a source of metals.

However few studies investigated the influence of properties of the drainage layer and other building elements on the release of pollutants, and the literature on thin soil layers is yet scarce $[31,25]$.

Dry deposition, weathering of building materials and atmospheric pollution in the form of particles, gases and aerosols contribute to cause the so called "first flush" phenomenon that is defined as a disproportioned increase of pollutants in terms of concentration or mass in the rising limb of an outflow hydrograph (see e.g. [32]). This phenomenon was not thought to occur in the vegetated roof because the roof material and biological activity were expected to smooth the pollutograph across the rain event. However, a first flush effect appears in the vegetated roof outflow and possibly can be linked to the presence of the drainage material [33].

Further investigations should concentrate on the materials used to construct the green roof, especially the substrate layer, and on the maintenance problems of extensive green roofs (e.g. fertilizers).

Although this review found that green roofs have both negative and positive effects, in terms of water quality, green roofs definitely have more positive than negative effects, and they play an important role in improving the quality of the urbanized environment.

\section{An experimental study in the Mediterranean environment}

In order to investigate the hydrologic response of a green roof in the Mediterranean climate, the University of Genova recently developed a joint laboratory and full-scale monitoring programme by installing a "controlled" test-bed with known rainfall input and a companion green roof experimental site in the town of Genoa, Italy.

\subsection{The laboratory test bed}

A small size green roof test bed was established at the laboratory of the Department of Civil, Environmental and Architectural Engineering (DICAT - University of Genova) in September 2007 aimed at performing runoff tests in a controlled environment using a rain simulator, with varying slope, depth and type of soil layers. 
The test bed is implemented with a $2.5 \mathrm{~m}^{2}$ plot, covered with an engineered system for extensive green roof installations manufactured by Harpo SEIC - Green Roof Division, primarily comprised of loose-laid synthetic specialized layers underneath the growing media. This growing media (total depth of $12 \mathrm{~cm}$ ) is a blend of lapillus, crushed brickwork, pumice, sand of brickwork, and for the organic matter, a blend of peat and vegetable compost. This substrate has a bulk density of $1.225 \mathrm{~g} / \mathrm{cm}^{3}$ and a total porosity equal to $64 \%$.

The plot is fully monitored and equipped with two cylindrical reservoirs for measuring inflow and outflow. For measuring inflow and outflow rates greater than $0.11 / \mathrm{min}$ two ultrasonic probes are installed to register water levels inside the cylindrical reservoirs, while for measuring the outflow (subsurface flow) at lower rates a tipping - bucket mechanism is employed [34].

In conformity with the DIN 4095, tests in a completely controlled environment (the laboratory) using a rain simulator have been carried out with the objective of better defining the behaviour of the system with varying slope, rain intensity and rain duration.

The determination of the runoff coefficient according to the DIN 4095 is briefly illustrated in the FLL (Forschungsgesellschaft Landschaftsentiwicklung Landschaftsbau) guidelines that represent a German reference in the framework of green roof technology.

The runoff coefficient $C_{d}$ defined as the percentage difference between discharged volume and rain volume is calculated for different time intervals related to the rain duration. In Table 1 the results obtained from the series of tests performed on the test-bed are summarized.

Table 1. List of runoff coefficients resulting from the green roof laboratory system.

\begin{tabular}{|c|c|c|c|c|c|}
\hline Test & $\begin{array}{c}\text { Duration } \\
\text { (min.s) }\end{array}$ & $\begin{array}{c}\mathbf{T} \\
\text { (year) }\end{array}$ & $\begin{array}{c}\mathbf{i} \\
(\mathrm{mm} / \mathrm{h})\end{array}$ & $\begin{array}{c}\text { Plot Slope } \\
(\%)\end{array}$ & $\begin{array}{l}\mathbf{C}_{\mathrm{d}} \\
(\%)\end{array}$ \\
\hline 1.(DIN 4095) & & & & 2 & 33 \\
\hline 2.(DIN 4095) & 15.00 & 30 & 108 & 5 & 34 \\
\hline 3.(DIN 4095) & & & & 10 & 36 \\
\hline 4. & & & & 2 & 35 \\
\hline 5. & 15.00 & 5 & 134 & 5 & 36 \\
\hline 6. & & & & 10 & 38 \\
\hline 7. & & & & 2 & 45 \\
\hline 8. & 20.46 & 5 & 134 & 5 & 47 \\
\hline 9. & & & & 10 & 48 \\
\hline 10. & & & & 2 & 36 \\
\hline 11. & 15.00 & 10 & 158 & 5 & 38 \\
\hline 12. & & & & 10 & 41 \\
\hline 13. & & & & 2 & 41 \\
\hline 14. & 18.29 & 10 & 158 & 5 & 44 \\
\hline 15. & & & & 10 & 44 \\
\hline 16. & & & & 2 & 39 \\
\hline 17. & 15.00 & 20 & 181 & 5 & 41 \\
\hline 18. & & & & 10 & 42 \\
\hline
\end{tabular}


Table 1. Cont.

\begin{tabular}{lccccc}
\hline 19. & & & 2 & 41 \\
20. & 16.00 & 20 & 181 & 5 & 43 \\
21. & & & & 10 & 44 \\
\hline 22. & & & 2 & 39 \\
23. & 15.00 & 30 & 194 & 5 & 40 \\
24. & & & & 10 & 42 \\
\hline
\end{tabular}

The tests are carried out for three system slopes, five rain rates and four duration values. In particular the characteristics of the experiments performed are:

- Slope: $2 \%, 5 \%$ and $10 \%$;

- Rain intensity: $108 \mathrm{~mm} / \mathrm{h}$ (according to DIN 4095), 134, 158, 181 and $194 \mathrm{~mm} / \mathrm{h}$ for a duration of 15 minutes and return periods respectively equal to 5, 10, 20 and 30 years as derived from rain event statistics in the Liguria region of Italy;

- Rain duration: 15 minutes (according to DIN 4095), 20'46', 18'29' and 16'00', so that the three rain intensities will produce the same total rain depth for these durations.

The runoff coefficient calculated for a time interval equal to the rain duration ranges between $33 \%$ and $48 \%$, varying with the rain intensity, rain duration and the plot slope. The highest runoff coefficient (48\%) obtained for the rain intensity of $134 \mathrm{~mm} / \mathrm{h}$, a duration of 20 ' 46 " and a slope of $10 \%$, is a quite small value if compared with the usual runoff coefficients of impermeable roofs. Results indicate that the runoff coefficient increases with the plot slope at fixed rainfall intensity and duration thus in accordance with results reported in the literature: Getter et al. [35] observed that the Curve Number, commonly used to estimate stom water runoff, increases with increasing slope. In addition, the runoff coefficient increases with rainfall intensity and duration as it could be easily expected.

\subsection{The full scale experimental site}

The rooftop of the Environmental Engineering laboratory at the University of Genova (Italy) is essentially a flat roof on three different levels, with an overall surface area of approximately $1000 \mathrm{~m}^{2}$. The existing green roof system was built in 1969 with a lower drainage layer in bricks for an initial depth of $8 \mathrm{~cm}$ and a growing medium of clayey ground for the remaining variable thickness layer with a maximum depth of $35 \mathrm{~cm}$ [36].

In May 2007 a new substrate system was implemented on the central portion of this green roof, with an extension of about $350 \mathrm{~m}^{2}$ and an average total depth of about $40 \mathrm{~cm}$ (see Figure 2). The new solution consists of a protection layer $\left(300 \mathrm{gr} / \mathrm{m}^{2}\right.$ geotextile), a drainage layer (implemented by lapillus for a depth of $20 \mathrm{~cm})$, a filter layer $\left(100 \mathrm{gr} / \mathrm{m}^{2}\right.$ geotextile) and a growing medium with mixed soil (lapillus, pumice, zeolite and $200 \mathrm{l} / \mathrm{m}^{3}$ of peat) for a depth of $20 \mathrm{~cm}$. The porous media employed at the experimental site are sorted and graded by Europomice Srl. In particular the growing medium is a composition of volcanic material and $16 \%$ of organic matter (peat). The central plot was divided into two equal halves for the purposes of research studies; in one half the volcanic blend consists of $70 \%$ 
lapillus and $30 \%$ pumice while in the other half the blend is $70 \%$ lapillus, $20 \%$ pumice and $10 \%$ zeolite.

The site is equipped with a meteorological station (for rain data, air temperature and humidity, global incoming solar radiation and air pressure) and with a hydraulic device for continuous outflow monitoring. The hydraulic device for the outflow monitoring consists of a rectangular channel equipped with a triangular weir and a level sensor. The channel is equipped with a small lateral orifice. The partial flow conveyed through the lateral orifice is discharged in a tipping bucket device: the size of the orifice has been designed to obtain suitable flow rates that are compatible with the bucket capacity. The triangular weir and the tipping bucket device were calibrated in the laboratory, the latter with reference to the recently developed World Meteorological Oraganization (WMO) recommendations (see e.g. [37]). In order to obtain a high accuracy throughout the measurement range, the triangular weir calibration curve is employed for effluent rates higher than $0.41 / \mathrm{s}$, while the tipping bucket calibration curve is used for lower effluent rates [38]. Subsurface water flow measurements are available at one minute resolution in time.

The monitoring programme started in May 2007 and is still in progress. In August 2008 one half of the rooftop was equipped with TDR (Time Domain Reflectometry) probes [39]. Based on the rooftop slope and the gutter positions the equipped half can be divided into two sub-catchments. In the centre of each sub-catchment, 4 TDR probes have been installed along a vertical profile.

Figure 2. The green roof experimental site at the University of Genova.

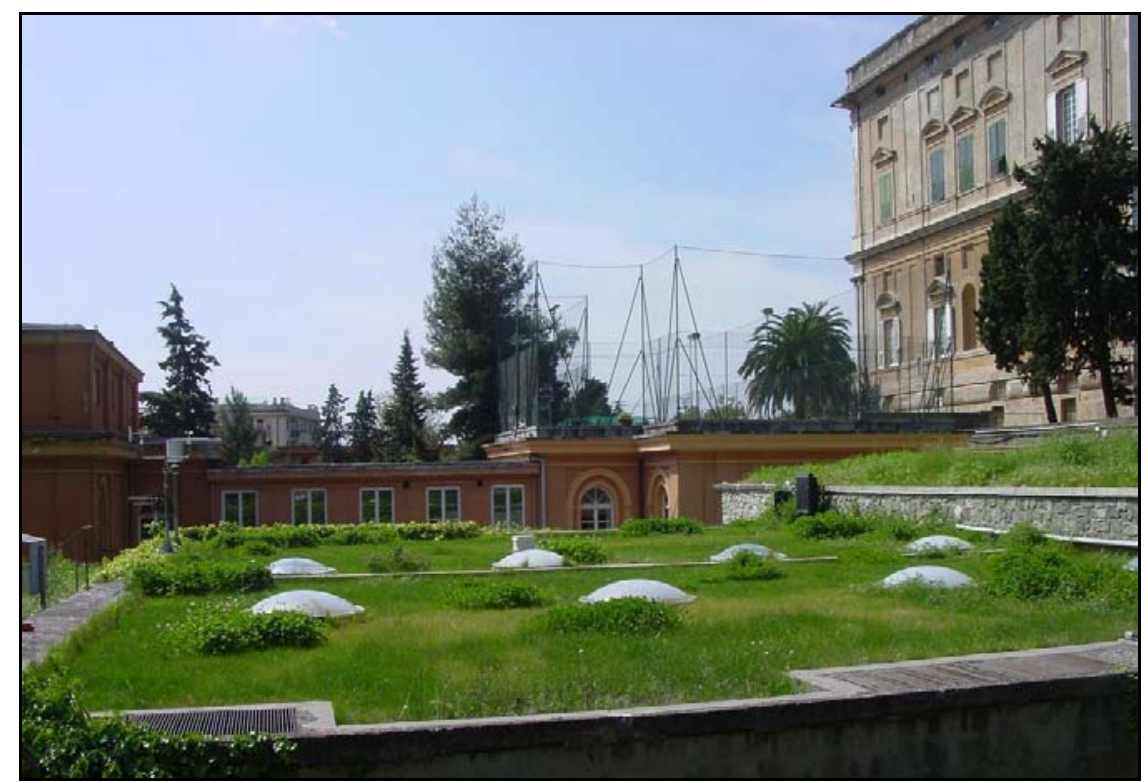

The first phase of the monitoring programme was carried out in May 2007 during the retrofitting works for the new green roof system, when the rooftop was only covered with the impermeable layer in order to measure the hydrologic response of the impervious roof. The impervious system was modelled by employing the EPA Storm Water Management Model (SWMM 5.0) to obtain a virtual reference impervious roof for comparison with the green roof hydraulic performance.

The hydrologic behaviour of the experimental green roof was examined on a event by event basis over a nineteen-months period. Five out of the thirty rainfall events monitored did not produce any 
outflow, in all events the rainfall volume was completely infiltrated (no runoff occurred) and only partially exfiltrated. The synthetic variables (retained volume, peak flow reduction and delay) used for describing the green roof hydraulic performance are defined below and experimental results are listed in Table 2.

Table 2. Events observed at the green roof of the University of Genova (Italy) and percentage of retained volume and peak flow reduction.

\begin{tabular}{|c|c|c|c|c|}
\hline $\begin{array}{c}\text { Event } \\
\text { (yyyy/mm/dd) }\end{array}$ & $\begin{array}{l}\text { Rain Depth } \\
\text { (mm) }\end{array}$ & $\begin{array}{c}\text { Retained Volume } \\
\text { (\%) }\end{array}$ & $\begin{array}{c}\text { Peak Reduction } \\
\text { (\%) }\end{array}$ & $\begin{array}{l}\text { Delay } \\
\text { (min) }\end{array}$ \\
\hline $2007 / 05 / 26$ & 9 & 100 & 100 & - \\
\hline $2007 / 05 / 28$ & 12.4 & 100 & 100 & - \\
\hline $2007 / 06 / 01$ & 42.4 & 99 & 99 & 345 \\
\hline $2007 / 06 / 05$ & 41.2 & 41 & 87 & 79 \\
\hline $2007 / 08 / 08$ & 13.2 & 100 & 100 & - \\
\hline 2007/08/09-10 & 14 & 95 & 98.7 & 793 \\
\hline $2007 / 08 / 20$ & 15.2 & 95 & 99.9 & 89 \\
\hline $2007 / 08 / 21$ & 32.6 & 96 & 99 & 436 \\
\hline $2007 / 09 / 27$ & 28.6 & 99 & 99.6 & 150 \\
\hline $2007 / 11 / 21$ & 8 & 100 & 100 & - \\
\hline $2007 / 11 / 22-23$ & 138.2 & 9.5 & 79 & 148 \\
\hline $2008 / 01 / 4-5$ & 32.8 & 70 & 76 & 754 \\
\hline $2008 / 01 / 11-12$ & 41.4 & 15 & 87 & 427 \\
\hline $2008 / 01 / 16$ & 40.4 & 4.6 & 78 & 139 \\
\hline $2008 / 02 / 04$ & 30.4 & 51 & 70 & 197 \\
\hline 2008/03/9-10 & 23.2 & 81 & 94 & 596 \\
\hline 2008/04/9-11 & 55 & 93 & 96 & 1716 \\
\hline $2008 / 04 / 21$ & 25.4 & 23 & 46 & 145 \\
\hline $2008 / 06 / 17$ & 35.6 & 19 & 77 & 91 \\
\hline $2008 / 09 / 03$ & 25.8 & 31 & 94 & 306 \\
\hline $2008 / 09 / 13$ & 23.2 & 100 & 100 & - \\
\hline $2008 / 09 / 19$ & 28.2 & 56 & 69 & 303 \\
\hline $2008 / 09 / 22$ & 16.6 & 19 & 84 & 145 \\
\hline $2008 / 10 / 28$ & 71.6 & 18 & 52 & 93 \\
\hline $2008 / 10 / 29$ & 74.8 & 0 & 91 & 71 \\
\hline $2008 / 11 / 04$ & 48 & 0 & 93 & 118 \\
\hline $2008 / 11 / 11-12$ & 72 & 0 & 61 & 174 \\
\hline $2008 / 11 / 29$ & 35 & 17 & 44 & 95 \\
\hline 2008/12/9-10 & 98.6 & 13 & 52 & 128 \\
\hline $2008 / 12 / 16-17$ & 32.6 & 0 & 72 & 212 \\
\hline Mean & - & 51.5 & 83.3 & 310 \\
\hline Std. Deviation & - & 40.7 & 17.9 & 357 \\
\hline
\end{tabular}


The retained volumes were calculated as the percentage difference between the volume of rain and the discharged volume, and range between $0 \%$ and $100 \%$, with an average value of $51.5 \%$. Note that the $0 \%$ retained volume is referred to few events with a dry antecedent period lower than 12 hours. The peak flow reduction was calculated as the percentage difference between the peak flow of the impervious reference roof (modelled) and the measured peak flow, with values ranging between $44 \%$ and $100 \%$, and an average value of $83.3 \%$.

Moreover, the relevant delays (310 min on average) that were determined as the difference in time between the hydrograph and hyetograph centroids, when compared with the usual time of concentration of urban catchments, promote the green roof as a source control system for storm water runoff. The performance of the green roof as a device for storm water control appear excellent, with average retained volumes and peak reduction respectively equal to $52 \%$ and $83 \%$.

In order to better illustrate the hydrologic behaviour of the green roof experimental site an observed rainfall event is reported in Figure 3. The 5 June 2007 event is the most intense among the monitored events, and results clearly show the detention capability of the green roof with respect to an impervious rooftop as demonstrated by the peak reduction and response delay.

Figure 3. Hyetograph and comparison between the green roof measured (grey filled area) and the impervious roof simulated hydrographs (continuous black line) for the 5 June 2007 event. In the graph, the peak reduction and delay are also indicated.

\section{June 2007}

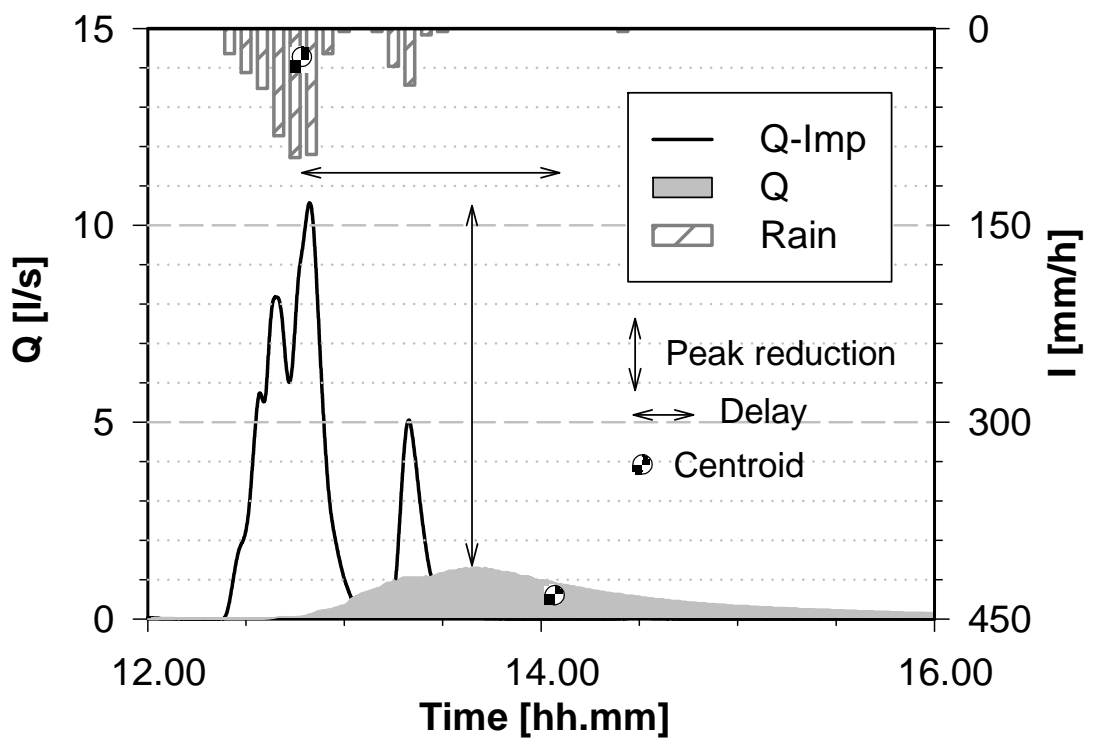

\section{Conclusions}

The practice of green roofs reveals great promises in mitigating the impact of increasing development in the urban environment. The research reviewed in this paper demonstrates that green roofs are generally effective in restoring the natural hydrologic functions and retaining pollutants in the urban areas. Interest in vegetated roofs is therefore increasing and more and more such installations are being established. 
As for storm water quantity, a green roof system is able to significantly reduce storm water runoff generation, with volume retention scores in the order of $40-80 \%$ of the total annual rainfall volume; furthermore a reduction of about $60 \%-80 \%$ in storm water runoff peak rates is also expected.

As for storm water quality, several studies have shown that green roof systems have the capacity to retain storm water pollutants but the extent of retention is still to be quantified in details. In addition investigations on the effect of different substrate mixtures and on the maintenance operations to minimize the risk of nutrients export, and especially phosphorus, is still needed.

The hydrologic performance of a laboratory green roof system (test-bed) and a full-scale experimental site were examined at the University of Genova (Italy) on a series of tests with varying rain intensity and plot slope and on an event basis over a nineteen-months period. The highest runoff coefficient (48\%) obtained for the local rain intensity with a return period of 5 years is a quite small value if compared with the usual runoff coefficients of impervious roofs. From the data monitored at the experimental site it clearly emerges, in agreement with literature data, that a green roof system is able to significantly control storm water runoff generation - even in Mediterranean regions - in terms of runoff volume reduction, outflow peak attenuation and increase of the time of concentration.

Extension of these results to the spatial scale of the urban watershed is needed to asses the role of green roof installations in preventing flooding phenomena in the urban areas and in limiting the impact of storm water on waste water treatment plants.

Further research needs have been identified. Long-term studies for all of the practices are justified, as very few studies exist on how these systems perform over extended periods of time. The many technical solutions available for the construction of green roof systems based on various layers, materials, thickness and vegetation species also require that more comprehensive datasets are provided to report quantitative information about the observed performance for the different technologies adopted. All this will be the basis for improved awareness in developing, designing and planning green roof solutions in a performance-oriented approach to sustainable construction.

\section{References}

1. Melbourne Water. WSUD Engineering Procedure: storm water, CSIRO Publishing: Collingwood, Australia, 2005.

2. Kleidorfer, M.; Moderl, M.; Sitzenfrei, R.; Urich, C.; Rauch, W. A case independent approach on the impact of climate change effects on combined sewer system performance. Water Sci. Technol. 2009, 60, 1555-1564.

3. Montalto, F.; Behr, C.; Alfredo, K.; Wolf, M.; Arye, M.; Walsh, M. Rapid assessment of the costeffectiveness of low impact development for CSO control. Landsc. Urban Plan. 2007, 82, 117-131.

4. Bengtsson, L. Peak flows from thin sedum-moss roof. Nord. Hydrol. 2005, 36, 269-280.

5. Stovin, V. The potential of green roofs to manage Urban Stormwater. Water Environ. J., 2010. In press.

6. Köehler, M. Urban storm water management by extensive green roofs. In Proceedings of the World Green Roof Congress/ Welt Gründach-Kongress, Basel, Switzerland, September 2005; pp. 150-156. 
7. Scholtz-Barth, K. Green roofs: Storm water management from the top down. Environ. Design and Construction 2001, January/February.

8. Centgraf, S.C.; Schmidt, M. Water management to save energy. A decentralized approach to an integrated sustainable urban development. In Proceedings of the Rio5- World Climate and Energy Event, Rio de Janeiro, Brazil, February 2005.

9. Deutsch, B.; Whitlow, H.; Sullivan, M; Savineau, A. Re-greening Washington D.C.: a green roof vision based on quantifying storm water and air quality benefits. In Proceedings of the 3rd Annual Greening Rooftops for Sustainable Communities Conference, Washington, D.C., USA, May 2005.

10. Tillinger, D.; Ostroff, G.; Beattie, D.; Berghage, R.; Mankiewicz, P.; Montalto, F. Hydrologic functions of green roofs in New York City. In Green Roofs in the New York metropolitan region: Research Report. Columbia University Center for Climate System Research and NASA Goddard Institute for Space Study, 2006, pp. 27-36.

11. Prowell, E.S. An analysis of storm water retention and detention pf modular green roof blocks. Master of Science Thesis, University of Georgia, USA, 2006.

12. Van Woert, N.D.; Rowe, D.B.; Andresen, J.A.; Rugh, C.L.; Fernandez, R.T.; Xiao, L. Green Roof Stormwater Retention: Effects of Roof Surface, Slope and Media Depth. J. Environ. Qual. 2005, 34, 1036-1044.

13. Monterusso, M.A.; Rowe, D.B.; Rugh, C.L.; Russell, D.K. Runoff water quantity and quality from green roof systems. Acta Hort. 2004, 639, 369-376.

14. Schade, C. Wasserrückhaltung und Abflußbeiwerte bei dünnschichtigen extensivbegrünungen. Stadt Grün 2000, 49, 95-100.

15. Liesecke, H.J. Das retentionsvermögen von dachbegrünungen. Stadt Grün 1998, 47, 46-53.

16. Villarreal, E.L.; Bengtsson, L. Response of a Sedum-green-roof to individual rain events. Ecol. Eng. 2004, 25, 1-7.

17. Alfredo, K.; Montalto, F.; Goldestein, A. Observed and modeled performance of prototype green roof test plots subjected to simulated low and high intensity precipitation in a laboratory experiment. J. Hydrol. Eng. 2010. In press.

18. Palla, A.; Lanza, L.G.; La Barbera, P. Traditional to green roof conversion scenarios for residential and industrial buildings. In Proceedings of the World Green Roof Congress 2008, London, UK, September 2008.

19. Mentens, J.; Raes, D.; Hermy, M. Green roofs as a tool for solving the rainwater runoff problem in the urbanized 21 st century? Landsc. Urban Plan. 2006, 77, 217-226.

20. Villarreal, E.L.; Semadeni-Davies, A.; Bengtsson, L. Inner city storm water control using a combination of best management practices. Ecol. Eng. 2004, 22, 279-298.

21. Carter, T.L.; Jackson, C.R. Vegetated roofs for storm water management at multiple spatial scales, Landsc. Urban Plan. 2007, 80, 84-94.

22. Palla, A.; Berretta, C.; Lanza, L.G.; La Barbera, P. Modeling storm water control operated by green roofs at the urban catchment scale. In Proceedings of the 11th International Conference on Urban Drainage, Edinburgh, UK, September 2008.

23. Dietz, M.E. Low Impact Development practices: a review of current research and recommendations for future directions. Water Air Soil Pollut. 2007, 186, 351-363. 
24. Hutchinson, D.; Abrams, P.; Retzlaff, R.; Liptan, T. Storm water monitoring two ecoroofs in Portland, Oregon, USA. In Proceedings of the Greening Rooftops for Sustainable Communities, Chicago, IL, USA, May 2003.

25. Moran, A.; Hunt, B; Smith, J. Hydrologic and water quality performance from greenroofs in Goldsboro and Raleigh, North Carolina. In Proceedings of the Greening Rooftops for Sustainable Communities, Washington, D.C., USA, May 2005.

26. Bliss, D.J.; Neufeld, R.D.; Ries, R.J. Storm Water Runoff Mitigation Using a Green Roof. Environ. Eng. Sci. 2009, 26, 407-417.

27. Emillson, T.; Berndtsson, C.J.; Mattsson, J.E.; Rolf, K. Effect of using conventional and controlled release fertiliser on nutrient runoff from various vegetated roof systems. Ecol. Eng. 2007, 29, 260-271.

28. Berndtsson, J.C.; Bengtsson, L.; Jinno, K. Runoff water quality from intensive and extensive green roofs. Ecol. Eng. 2009, 35, 369-380.

29. Teemusk, A.; Mander, Ü. Rainwater runoff quantity and quality performances from a greenroof: The effects of short-term events. Ecol. Eng. 2007, 30, 271-277.

30. Alsup, S.; Ebbs, S.; Retzlaff, W. The exchangeability and leachability of metals form select green roof growth substrates. Urban Ecosyst. 2010, 13, 91-111.

31. Berndtsson, J.C.; Emilsson, T.; Bengtsson, L. The influence of extensive vegetated roofs on runoff water quality. Sci. Total Environ. 2006, 355, 48-63.

32. Gnecco, I.; Berretta, C.; Lanza, L.G.; La Barbera, P. Storm water pollution in the urban environment of Genoa, Italy. Atm. Res. 2005, 77, 60-73.

33. Berndtsson, J.C.; Bengtsson, L.; Jinno, K. First flush effect from vegetated roofs during simulated rain events. Nord. Hydrol. 2008, 39, 171-179.

34. Palla, A.; Lanza, L.G; La Barbera, P. Green roof storm water detention: laboratory and full-scale experiences in the Mediterranean climate. In Proceedings of the World Green Roof Congress 2008, London, UK, September 2008.

35. Getter, K.L.; Rowe, D.B.; Andresen, J.A. Quantifying the effect of slope on extensive green roof storm water retention. Ecol. Eng. 2007, 31, 225-231.

36. Palla, A.; Lanza, L.G.; La Barbera, P. A green roof experimental site in the Mediterranean climate. In Proceedings of the 11th International Conference on Urban Drainage, Edinburgh, UK, September 2008.

37. Lanza, L.G.; Stagi, L. High resolution performance of catching type rain gauges from the laboratory phase of the WMO Field Intercomparison of Rain Intensity Gauges. Atmos. Res. 2009, 94, 555-563.

38. Palla, A. Unsaturated flow in engineered porous media for hydrologic restoration. PhD thesis. University of Genova, Italy, 2009.

39. Palla, A.; Gnecco, I.; Lanza, L.G. Unsaturated 2-D modelling of subsurface water flow in the coarse-grained porous matrix of a green roof. J. Hydrol. 2009, 379, 193-204.

(C) 2010 by the authors; licensee Molecular Diversity Preservation International, Basel, Switzerland. This article is an Open Access article distributed under the terms and conditions of the Creative Commons Attribution license (http://creativecommons.org/licenses/by/3.0/). 